Vol. 1 No. 2, Juli 2021, hlm. $103-108$

DOI: https://doi.org/10.33330/j-com.v2i1.1207

Available online at http:// jurnal.stmikroyal.ac.id/index.php/j-com

\title{
IMPLEMENTASI SUPPLY CHAIN MANAGEMENT BERBASIS WEB UNTUK PENGELOLAAN STOK DAN DISTRIBUSI SPARE PART HANDPHONE PADA ERWIN PONSEL
}

\author{
Nur Laila Sari ${ }^{1}$, Herman Saputra ${ }^{2 *}$, Hommy Dorthy Ellyany Sinaga ${ }^{3}$ \\ ${ }^{1}$ Mahasiswa Prodi Sistem Komputer, STMIK Royal \\ ${ }^{2}$ Prodi Sistem Komputer, STMIK Royal \\ ${ }^{3}$ Prodi Sistem Informasi, STMIK Royal \\ *email: hermansaputra4@gmail.com
}

\begin{abstract}
Erwin Ponsel which distribute handphone spare parts is facing problem of managing the handphone spare part inventory that is often out of stock and inventory orders from suppliers not deliver on time that make Erwin Ponsel could not fullfill the customer demand at time. This study aims to help provide solutions for this problem is to implement the SCM application web base to the inventory and distribution of handphone spare parts. The research method used is a qualitative method and performs system design with the waterfall method. The research data taken includes supplier data, handphone spare part purchases data, distribution data and customer data. This application is built using the PHP programming and MySQL database. With the implementation of this application, a relationship that is interconnected between suppliers and Erwin Ponsel has been built in a timely manner so as to facilitate stock management and distribution ofhandphone spare part at Erwin Ponsel.
\end{abstract}

Keywords: Distribution Spare Part Handphone ; Stock Spare Part Handphone; SCM

\begin{abstract}
Abstrak: Erwin Ponsel yang bergerak pada bidang pendistribusian spare part handphone memiliki permasalahan pada penanganan persediaan spare part handphone dimana sering terjadi kehabisan persediaan dan pemesanan persediaan dari pemasok tidak tiba pada waktunya sehingga mengakibatkan Erwin Ponsel tidak dapat memenuhi permintaanpelanggan. Penelitian ini bertujuan untuk membantu memberikan solusi terhadap permasalahan tersebut dengan menerapkan aplikasi SCM berbasis web pada sistem persediaan dan distribusi spare part handphone. Metode penelitian yang digunakan adalah metode kualitatif dan melakukan perancangan sistem dengan metode waterfall. Data penelitian yang diambil meliputi data supplier, data pembelian spare part handphone, data distribusi dan data pelanggan. Aplikasi ini dibangun menggunakan bahasa pemrograman PHP dan database MySQL. Dengan adanya implementasi dari aplikasi ini, maka telah terbangun satu hubungan yang saling terkoneksi antara supplier dengan Erwin Ponsel secara tepat waktu sehingga memudahkan pengelolaan stok dan distribusi spare part handphone di Erwin Ponsel.
\end{abstract}

Kata kunci :Distribusi Spare Part Handphone; Stok Spare Part Handphone; SCM 
Vol. 2 No. 1, Juli 2021, hlm. 103-108

DOI: http://dx.doi.org/10.33330/j-com.v2i1.1207

Available online at http:// jurnal.stmikroyal.ac.id/index.php/j-com

\section{PENDAHULUAN}

Erwin Ponsel merupakan toko yang bergerak dalam bidang pembelian dan pendistribusian spare part handphone yang beralamat di jalan Terang Bulan Desa Suka Maju, Kecamatan Tanjung Tiram, Kabupaten Batu Bara. Usaha ini berdiri pada tanggal 10 Oktober 2015 dengan pemilik bernama Darwin Jambak.

Berdasarkan hasil pengamatan dan wawancara dengan karyawan Erwin Ponsel bahwa pada sistem manajemen persediaannya sering terjadi kehabisan stok barang dikarenakan banyaknya permintaan dari pelanggan dan sering terjadi kelebihan stok barang dikarenakan waktu pengadaan barang yang kurang tepat dalam setiap periode bulannya. Padahal persediaan merupakan aset utama pada perusahaan untuk melancarkan proses bisnis serta memenuhi kebutuhan pelanggan [1]. Selain itu, proses pendataan barang masih dilakukan dengan cara pencatatan secara manual sehingga sering terjadi kesalahan dalam menentukan jumlah persediaan barang yang akan dipesan.

Proses pengadaan barang dilakukan berdasarkan pada data pendistribusian bulanan dan seringkali tidak bisa memenuhi kebutuhan pelanggan secara efektif dan efisien. Sehingga dibutuhkan sebuah sistem yang telah terintegrasi untuk mengetahui batas minimum persediaan yang dibutuhkan.

Dari masalah di atas Erwin Ponsel mendapatkan dampak negatif bahwa dengan adanya masalah tersebut tentu saja dapat merugikan Erwin Ponsel baik dari segi pelayanan maupun segi keuangan. Masalah ketersediaan barang inilah yang akan diatasi dengan penerapan SCM untuk mengatur ketersediaan barang dan meningkatkan profitabilitas dalam pendistribusian barang.

Penerapan SCM dilakukan untuk mencapai tujuan suatu organisasi dengan memanfaatkan sumber daya semaksimal mungkin sehingga pendapatan suatu perusahaan semakin meningkat [2]. Penyediaan produk yang tepat bagi pelanggan di waktu yang tepat dan biaya yang ekonomis merupakan salah satu hal yang membuat perusahaan distributor bertahan.

Ketersediaan produk dan harga jual yang ekonomis hanya dapat terjadi jika ada koordinasi yang baik antara perusahaan distributor dengan pihak-pihak dalam rantai pasoknya [3]. Koordinasi antara pihak-pihak dalam rantai pasok melibatkan koordinasi pada persediaan dan informasi tentang pasar yang berguna bagi perencanaan perusahaan. Koordinasi informasi yang baik dari setiap pemasok akan mengurangi resiko kerugian yang diakibatkan dari adanya kekurangan dan kelebihan persediaan barang. Kekurangan persediaan barang pada distributor akan berakibat kehilangan penjualan, sedangkan kelebihan persediaan barang akan berakibat menumpuknya barang dan meningkatkan biaya pemeliharaan persediaan.

Dari beberapa penelitian [4], menunjukkan bahwa sistem yang dirancang menggunakan SCM memberikan kemudahan bagi pihak pemasok untuk menjamin persediaan dan kelancaran arus bahan baku pakaian. Penelitian Suryaman memberikan hasil bahwa sistem yang dibangun memudahkan Dodi Sport dalam pengelolaan data barang, diantaranya dalam proses pengecekan barang yang masih tersedia dan pengeluaran barang dapat dilihat dari laporan barang tanpa harus mengecek langsung ke gudang. Selain itu, pihak pemasok dengan bagian gudang dapat berkomunikasi dan saling memberikan informasi tentang stok barang dengan mudah [5]. 
Vol. 2 No. 1, Juli 2021, hlm. 103-108

DOI: http://dx.doi.org/10.33330/j-com.v2i1.1207

Available online at http:// jurnal.stmikroyal.ac.id/index.php/j-com

Sistem rantai pasok yang dibangun dapat memudahkan PMI dalam mengatur persediaan darah. Selain itu, sistem yang dibangun menyediakan fitur untuk mengisi data pasien yang membutuhkan tanpa harus datang ke PMI secara langsung [6]. Penerapan SCM dapat memberikan kemudahan dalam meningkatkan proses distribusi spare part handphone pada Erwin Ponsel.

\section{METODE}

SCM ialah jaringan perusahaan-perusahaan yang saling berkontribusi dalam menciptakan produk hingga menghantarkan produk ke pemakai akhir. Perusahaanperusahaan yang terlibat dalam proses SCM yaitu pemasok (supplier), pabrik (manufacturer), distributor, retailer, dan customer [3].

Manfaat dari SCM adalah [3]: (1) Mengembangkan Supplier Partnership Dengan mengadakan kerjasama dengan pemasok dan mengembangkan strategi dapat melancarkan pendistribusian barang dalam SCM., (2) Mengurangi Inventory Inventory adalah aset terbesar dari perusahaan yang berkisar antara 30\% - 40\%., (3) Menjamin Kelancaran Penyediaan Barang Kelancaran penyediaan barang dimulai dari pemasok, barang asal (pabrik pembuat), distributor, retailer, sampai ke konsumen akhir.,(4) Menjamin Mutu Mutu barang yang telah jadi tidak hanya ditentukan dari proses produksinya saja, akan tetapi ditentukan juga oleh mutu bahan mentahnya dan mutu dalam kualitas pengirimannya., (5) Mengurangi Jumlah Pemasok Tujuan mengurangi jumlah pemasok yaitu untuk mengurangi ketidakseragaman, biaya negosiasi, dan pelacakan (tracking).

\section{HASIL DAN PEMBAHASAN}

Halaman login merupakan halaman untuk klarifikasi hak pengguna atau user dalam melakukan login untuk masuk ke sistem. Setelah melakukan login pengguna dapat menggunakan sistem. Dalam sistem Implementasi SCM Berbasis Web Untuk Pengelolaan Stok Dan Distribusi Spare Part Handphone Pada Erwin Ponsel ini terdapat empat pengguna atau user yang melakukan login diantaranya yaitu: Pemilik, Admin Gudang, Supplier, dan Admin Penjualan.
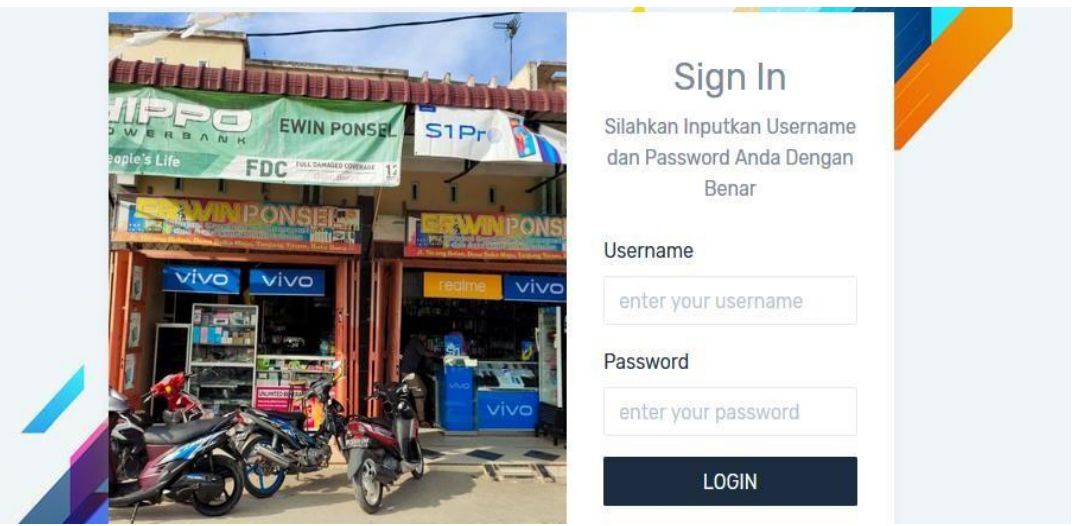

Gambar 1. Halaman Login 
Vol. 2 No. 1, Juli 2021, hlm. 103-108

DOI: http://dx.doi.org/10.33330/j-com.v2i1.1207

Available online at http:// jurnal.stmikroyal.ac.id/index.php/j-com

Halaman utama Admin Penjualan dapat mengelolah data customer, mengelolah data penjualan, mencetak faktur penjualan dan laporan penjualan, dan ubah password.

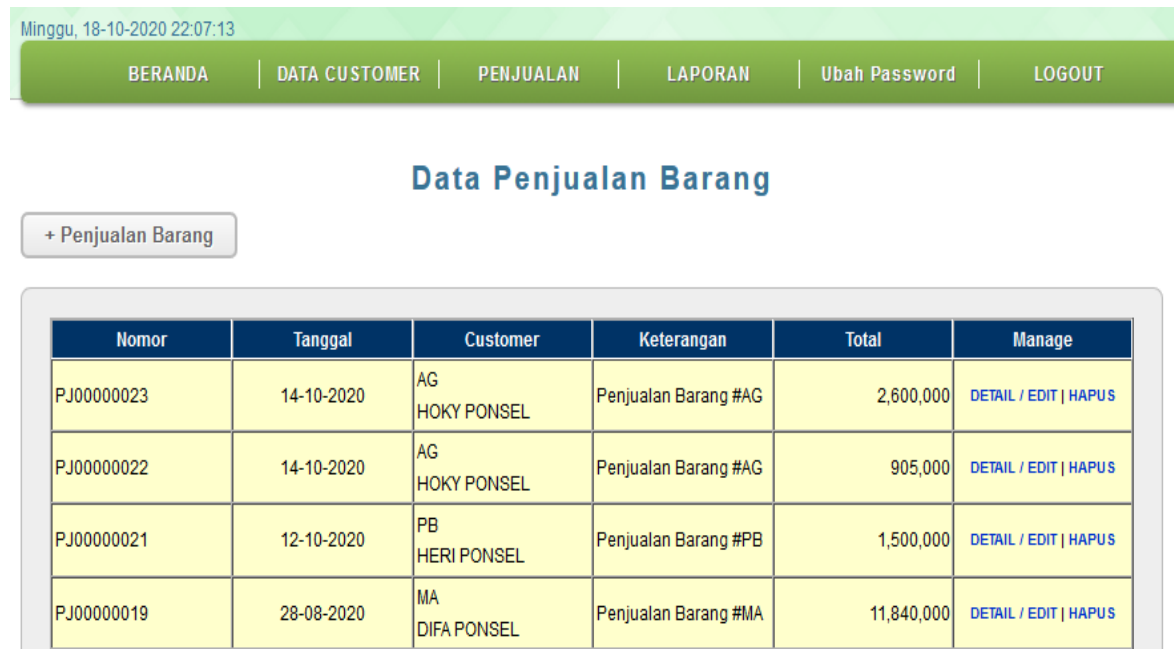

Gambar 2. Halaman Utama Admin Penjualan

Halaman Admin Penjualan dalam melakukan proses penjualan, dapat menginput data customer, nama spare part yang dijual, dan perhitungan transaksi.

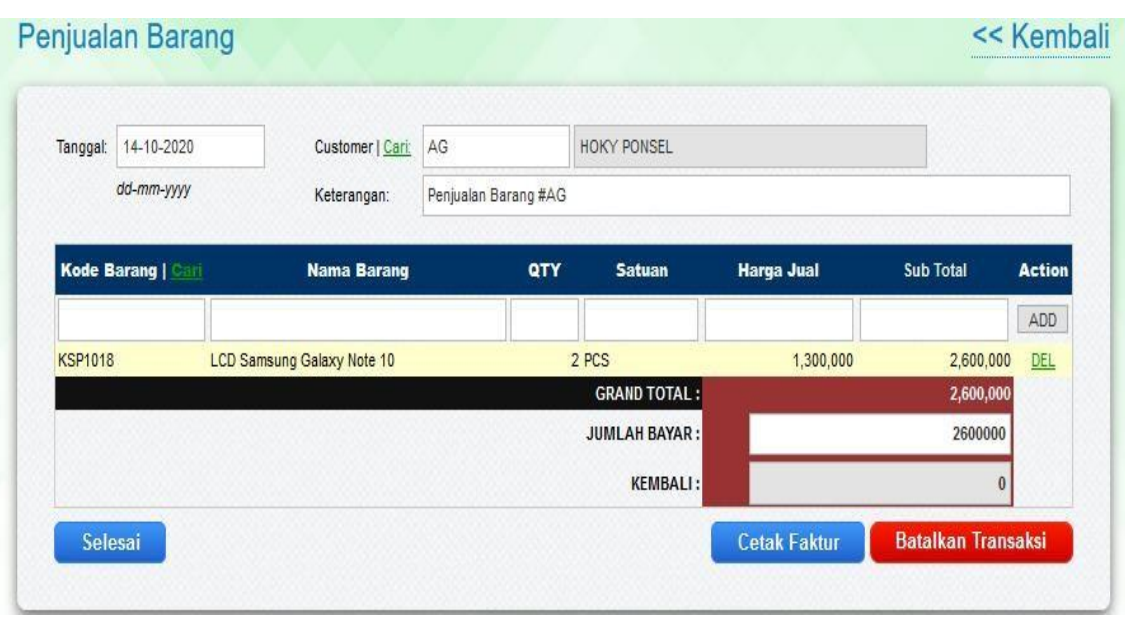

Gambar 3. Halaman Admin Penjualan Mengolah Data Penjualan

Tampilan laporan penjualan merupakan laporan untuk melihat data penjualan setiap periode yang selanjutnya di cetak dan diserahkan kepada pemilik Erwin Ponsel. 
Vol. 2 No. 1, Juli 2021, hlm. 103-108

DOI: http://dx.doi.org/10.33330/j-com.v2i1.1207

Available online at http:// jurnal.stmikroyal.ac.id/index.php/j-com

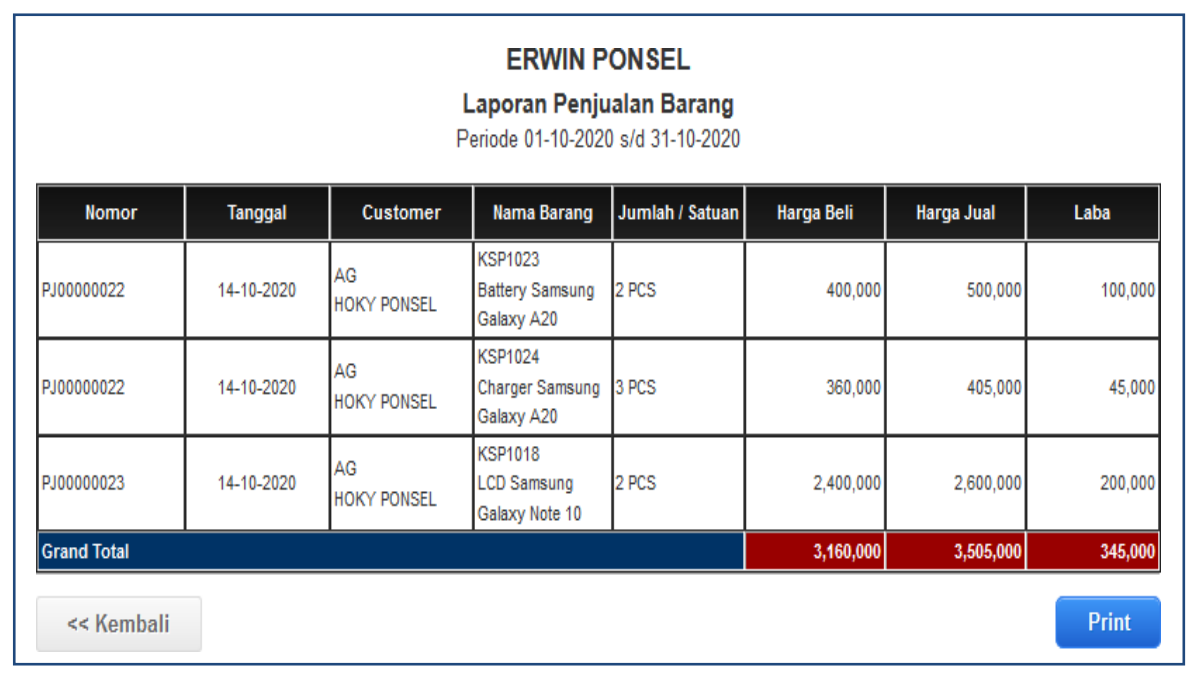

Gambar 4. Laporan Penjualan

\section{SIMPULAN}

Kesimpulan yang dapat diambil adalah sebagai berikut: (1) Perancangan sistem SCM berbasis web ini dibangun untuk mengkoordinasi hubungan antara supplier dengan admin gudang pada. Dengan dibangunnya sistem SCM berbasis web ini maka Erwin Ponsel dapat melakukan order kepada supplier yang berkomitmen menyediakan spare part handphone tepat waktu., (2) Perangkat lunak SCM berbasis web telah berhasil dibangun sebagai sistem informasi yang dapat membantu dalam pengelolaan stok dan distribusi spare part handphone pada Erwin Ponsel.

\section{DAFTAR PUSTAKA}

[1] G. Sirait, "PENGENDALIAN PERSEDIAAN OBAT DENGAN PENDEKATAN ECONOMIC ORDER QUANTITY," J. REKAYASA Sist. Ind., vol. 4, no. 2, 2019, doi: 10.33884/jrsi.v4i2.1276.

[2] E. M. Putri, "PERANCANGAN MODEL DISTRIBUSI BERBASIS SUPPLY CHAIN MANAGEMENT MENGGUNAKAN BAHASA PEMOGRAMAN PHP MySQL," J. Teknol. Inf. dan Pendidik., vol. 9, no. 2, 2016, [Online]. Available: http://tip.ppj.unp.ac.id/index.php/tip/article/view/73.

[3] P. Parwati, C. I. Sodikin, and S. Akmaludin, "Perancangan Model Electronic Supply Chain Managament UD. Mr Chili Cilacap," 2019, [Online]. Available: http://hdl.handle.net/11617/10710.

[4] E. Y. Astuty and O. Afiatinisa, "Rancang Bangun Sistem Peramalan Permintaan Dan Pengendalian Persediaan Manajemen Rantai Pasok Pada Olin Modiste," J. REKAYASA Inf., vol. 6, no. 1, 2017, [Online]. Available: https://ejournal.istn.ac.id/index.php/rekayasainformasi/article/view/346.

[5] A. Suryaman, A. Wahyudin, and D. Nugraha, "IMPLEMENTASI SUPPLY 
Vol. 2 No. 1, Juli 2021, hlm. 103-108

DOI: http://dx.doi.org/10.33330/j-com.v2i1.1207

Available online at http:// jurnal.stmikroyal.ac.id/index.php/j-com

CHAIN MANAGEMENT PADA TOKO ALAT-ALAT OLAH RAGA BERBASIS WEB. STUDI KASUS PADA DODI SPORT," NUANSA Inform. J. Teknol. DAN Inf., vol. 12, no. 1, 2018, [Online]. Available: https://journal.uniku.ac.id/index.php/ilkom/article/view/1343/1005.

[6] R. Nababan, R. Rumapea, and I. Sarkis, "Sistem Informasi Persediaan Donor Darah Berbasis Supply Chain Management Di Palang Merah Indonesia ( Pmi ) Medan," J. Method., vol. 4, no. 1, 2018. 